\title{
Socioeconomic status and preterm birth: New Zealand trends, 1980 to 1999
}

\author{
E D Craig, J M D Thompson, E A Mitchell
}

See end of article for authors' affiliations

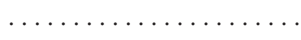

Correspondence to: Dr E Craig, Department of Paediatrics, University of Auckland, Private Bag 92019, Auckland, New Zealand;

e.craig@auckland.ac.nz

Accepted

23 November 2001
Background: While a number of countries have reported rising preterm birth rates over the past two decades, none has examined the effects of socioeconomic status on preterm birth at a national level. Aim: To document the changing incidence of preterm birth in New Zealand over the past 20 years and to determine whether particular socioeconomic or ethnic subsections of the population have contributed disproportionately to the changes seen.

Methods: Birth registration data routinely available from the New Zealand Health Information Service were analysed for the period 1980-99. Information for a total of 1079478 singleton live births was linked by Domicile Code to the New Zealand Deprivation Index, a small area index of deprivation.

Results: Singleton preterm birth rates rose by $37.2 \%$ during the 20 year period, from $4.3 \%$ in 1980 to $5.9 \%$ in 1999 . Rates increased by $71.9 \%$ among those living in the most affluent areas, but by only $3.5 \%$ among those living in the most deprived areas, resulting in the disappearance of a socioeconomic gradient in preterm birth that had existed during the early 1980s.

Conclusions: This study challenges traditional thinking on the associations between socioeconomic status and preterm birth. Further research is necessary if the changes that have occurred in New Zealand over the past 20 years are to be fully understood. n $19804.3 \%$ of singleton live births in New Zealand occurred prior to 37 weeks gestation. Since that time several developed countries have reported increasing rates of preterm birth. In the USA preterm birth rates have increased by $23 \%$ since 1981 , with rates among non-Hispanic whites increasing 20\% since 1989. ${ }^{1}$ In Canada, singleton preterm birth rates rose by $5 \%$ between 1981 and $1994 .^{2}$ In contrast, rates in Australia ${ }^{3}$ have remained static over the past decade, while France reported declining preterm birth rates between 1981 and 1989. ${ }^{4}$ None of these studies, however, examined the influence of socioeconomic status on the changes seen.

A number of reasons have been given for the rising preterm birth rates in North America. While an increase in the number of multiple gestations is a likely contributor, trends persist when analysis is limited to singleton births. ${ }^{2}$ Similarly, increasing reliance on ultrasound dating of pregnancy, rather than the traditionally used last menstrual period (LMP) may have increased preterm birth rates as the proportion of women scanned increased. ${ }^{5}$ In addition, increasing obstetric intervention over the same time period (as indicated by declining stillbirth rates and rising numbers of caesarean sections) may have been responsible for the birth of a number of preterm infants who would not otherwise have survived. ${ }^{2}$

To date, no similar analysis of preterm birth rates has been published for New Zealand. Such information is vital not only for clinical practice, but for the future delivery of health services in this country. Furthermore, with the recent introduction of the Deprivation Index, ${ }^{6}$ New Zealand births can now be assigned a small area index of deprivation, making it possible to track socioeconomic differences in preterm birth over a 20 year period.

\section{METHODS}

Birth registration data for this study were obtained from the New Zealand Health Information Service, a group within the Ministry of Health responsible for the collection and dissemination of health related data. Information was available for l 079478 singleton live births and 5146 singleton stillbirths between 1980 and 1999. Of these 1084624 births, 28084 $(2.6 \%)$ were excluded on the basis of incomplete gestational age information. The majority of these omissions (73\%) occurred during 1998 as a result of changes in data collection arrangements at that time.

Collected birth data were allocated a Statistics New Zealand Area Unit Code, or Domicile Code based on the usual residential address at the time of delivery. This allowed the linking of births with the New Zealand Deprivation Index (NZDep), a small area index of deprivation based on a number of socioeconomic variables as measured by the 1991 and 1996 censuses. ${ }^{6}$ For most analyses this index is converted into a decile scale, with decile 1 representing the least deprived $10 \%$ of small areas and decile 10 representing the most deprived $10 \%$ of small areas.

Because the NZ Deprivation Index was based on Statistics New Zealand's smallest geographic unit, the meshblock (covering a population of approx. 100), and the Health Information Service's Birth Data were assigned a Census Area Unit Code (representing the next administrative tier, and a population of approx. 3000), births could not be assigned directly to a Deprivation Index decile. This necessitated the creation of a number of weighted averages, with each Census Area Unit being assigned a Deprivation Index decile based on the averaged deprivation scores of the various meshblocks within its boundaries. As in the original scale, those residing in the least deprived $10 \%$ of Census Area Units received a Deprivation Index decile of 1 , while those residing in the most deprived $10 \%$ of Census Area Units received a Deprivation Index decile of 10. For births occurring prior to 1994 deciles were derived from the NZDep9l Index, while those from 1994 onwards utilised the NZDep96.

Analysis of factors relating to preterm birth was then carried out using logistic regression, with births under 37 weeks gestation being the outcome variable of interest. Explanatory variables included year of birth, Deprivation Index decile, parity, age of mother, and infant gender. Year of birth and decile were treated as continuous variables while parity (nulliparous versus multiparous) and gender were 


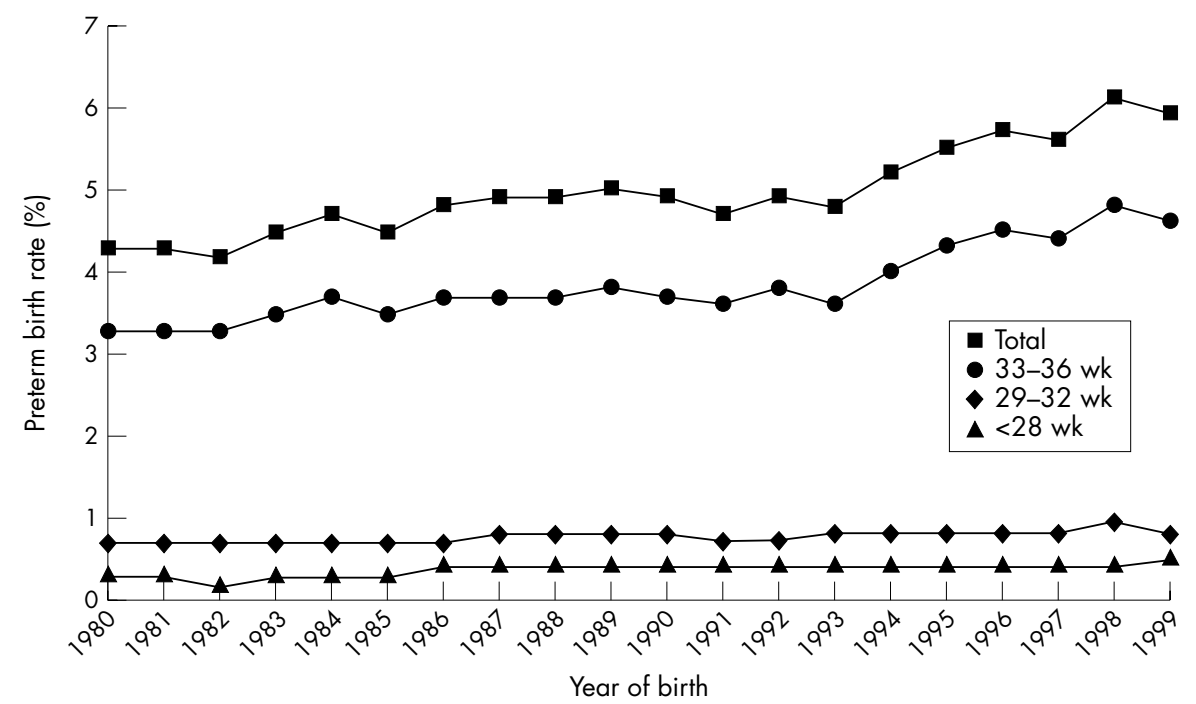

Figure 1 Rates of preterm birth by gestational age group; New Zealand singleton live births 1980-99.

treated as categorical. Maternal age, because of its $U$ shaped association with preterm birth was also treated as categorical, rather than using linear or quadratic terms. Interactions terms placed in subsequent models included year*decile, year*age, year*parity, decile*age, decile*parity to allow for changes in maternal age and parity over the 20 year period, as well as for differences in age and parity between Deprivation Index deciles.

The babies' ethnicity was also reported in this dataset, but changes in definition during 1995 made information collected prior to this date incomparable with that collected afterwards. Prior to 1995 ethnicity was defined by ancestry (with those having half or more Maori or Pacific blood meeting ethnic group criteria) while after 1995 parents were asked to which ethnic groups their babies belonged and a priority rating introduced for those reporting multiple ethnic affiliations. Thus while ethnicity is an essential element in any discussion on preterm birth, changes in definition during the study period prevented detailed analysis of its effects during the period of most rapid change.

\section{RESULTS}

Due to the large sample size $(n=1051394)$ all associations seen in this study reached statistical significance unless otherwise indicated, and thus it is necessary to focus on the size of the effect rather than the level of significance for any particular association.

Figure 1 summarises rates of preterm birth by gestational age group over the past 20 years. Preterm birth rates during this period rose by $37.2 \%$, from $4.3 \%$ in 1980 to $5.9 \%$ in 1999 . Not all gestational age categories contributed equally to this rise, with rates among those in the 20-28 week category increasing only marginally in absolute terms, from a rate of $0.3 \%$ in 1980 to a rate of $0.5 \%$ by 1999 . In proportional terms however, this represented an $81.5 \%$ increase over 1980 figures. For those in the 33-36 week category, preterm rates rose by $37.3 \%$, from $3.3 \%$ in 1980 to $4.6 \%$ in 1999 . By contrast, rates for those in the 29-32 week category changed very little, either in absolute or relative terms.

Table 1 summarises univariate and multivariate models (minus interaction terms) for the associations between infant gender, maternal age, parity, year of birth, Deprivation Index decile, and preterm birth. As noted previously a U shaped association exists between maternal age and preterm birth, with excess risk being present among those under 25 and over 35 years. While the magnitude of this association is diminished with multivariate modelling, it still remains significant. Similarly parity exhibits a U shaped association,
Table 1 Odds ratios for preterm birth: univariate and multivariate models

\begin{tabular}{|c|c|c|}
\hline $\begin{array}{l}\text { Continuous } \\
\text { variables }\end{array}$ & $\begin{array}{l}\text { Univariate model } \\
\text { (95\% Cl) }\end{array}$ & $\begin{array}{l}\text { Multivariate model } \\
(95 \% \mathrm{CI})\end{array}$ \\
\hline \multicolumn{3}{|l|}{ Infant gender } \\
\hline Male & 1.13 (1.11 to 1.15 ) & $1.13(1.11$ to 1.15$)$ \\
\hline Female & 1.00 & 1.00 \\
\hline \multicolumn{3}{|l|}{ Maternal age } \\
\hline$<20$ years & 1.55 (1.50 to 1.60$)$ & 1.28 (1.24 to 1.33$)$ \\
\hline $20-24$ years & 1.16 (1.13 to 1.19$)$ & $1.07(1.04$ to 1.10$)$ \\
\hline $25-29$ years & 1.00 (0.98 to 1.03 ) & 0.98 (0.95 to 1.00$)$ \\
\hline $30-34$ years & 1.00 & 1.00 \\
\hline $35+$ years & 1.23 (1.19 to 1.27$)$ & 1.21 (1.17 to 1.25$)$ \\
\hline \multicolumn{3}{|l|}{ Parity } \\
\hline 0 & 1.47 (1.44 to 1.50$)$ & 1.40 (1.37 to 1.43$)$ \\
\hline 1 & 1.00 & 1.00 \\
\hline 2 & $0.94(0.91$ to 0.97$)$ & $0.94(0.91$ to 0.97$)$ \\
\hline 3 & 1.02 (0.97 to 1.07$)$ & 1.01 (0.96 to 1.05 ) \\
\hline $4+$ & $1.22(1.16$ to 1.29$)$ & $1.14(1.0$ to, 1.21$)$ \\
\hline $\begin{array}{l}\text { Continuous } \\
\text { variables }\end{array}$ & Beta $(95 \% \mathrm{Cl})$ & Beta $(95 \% \mathrm{Cl})$ \\
\hline Year of birth & $\begin{array}{l}1.018(1.016 \text { to } \\
1.019)\end{array}$ & $\begin{array}{l}1.016(1.015 \text { to } \\
1.018)\end{array}$ \\
\hline $\begin{array}{l}\text { Deprivation Index } \\
\text { decile }\end{array}$ & $\begin{array}{l}1.029(1.026 \text { to } \\
1.033)\end{array}$ & $\begin{array}{l}1.022 \text { (1.019 to } \\
1.026)\end{array}$ \\
\hline
\end{tabular}

with the highest risks being experienced by nulliparous women. Multivariate modelling only reduces this additional risk marginally. Year of birth and Deprivation Index decile both increase risk linearly. The risk associated with year was equivalent to a 1.37 increase in risk for the 20 year period, while that associated with decile was equivalent to a 1.24 difference between those living in decile 10 areas and those living in decile 1 .

Figure 2 summarises changes in preterm birth rates by Deprivation Index decile between 1980 and 1999. During this period rates of preterm birth rose from $5.6 \%$ to $5.9 \%$ among those living in the most deprived areas (a 5.4\% increase), from $4.3 \%$ to $5.9 \%$ among those living in average areas (a $37.2 \%$ increase) and from $3.2 \%$ to $5.5 \%$ among those living in the least deprived areas (a 71.9\% increase). Thus while in 1980 a marked social gradient in preterm birth existed, by 1999 this had virtually disappeared.

Table 2 shows odds ratios for preterm birth by Deprivation Index decile for the years 1980, 1990, and 1999. These odds 


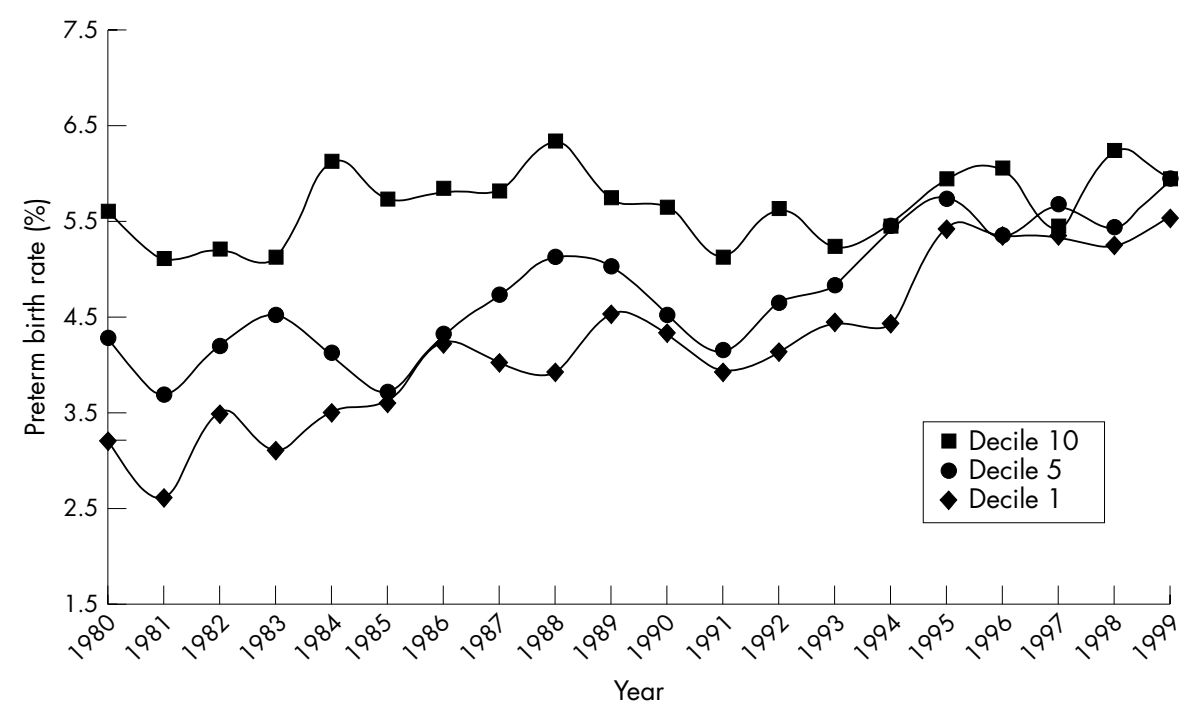

Figure 2 Rates of preterm birth by Deprivation Index; New Zealand singleton live births 1980-99.

\begin{tabular}{|c|c|c|c|c|c|}
\hline \multirow[b]{2}{*}{ Year } & \multirow[b]{2}{*}{$\begin{array}{l}\text { NZDep } \\
\text { decile }\end{array}$} & \multicolumn{4}{|c|}{ Gestational age category } \\
\hline & & $\begin{array}{l}\text { All preterm } \\
\text { OR* }^{*}\end{array}$ & $\begin{array}{l}20-28 w^{* *} \\
(n=2693) \\
\text { OR* }\end{array}$ & $\begin{array}{l}29-32 w k \\
(n=12669) \\
\text { OR* }\end{array}$ & $\begin{array}{l}33-36 w k \\
(n=36266) \\
\text { OR* }\end{array}$ \\
\hline 1980 & 1 & 1.00 & 1.00 & 1.00 & 1.00 \\
\hline 1980 & 5 & 1.26 & 1.12 & 1.25 & 1.19 \\
\hline 1980 & 10 & 1.67 & 1.28 & 1.66 & 1.48 \\
\hline 1990 & 1 & 1.19 & 1.58 & 1.19 & 1.17 \\
\hline 1990 & 5 & 1.43 & 1.82 & 1.42 & 1.32 \\
\hline 1990 & 10 & 1.79 & 2.17 & 1.76 & 1.55 \\
\hline 1999 & 1 & 1.40 & 2.39 & 1.40 & 1.34 \\
\hline 1999 & 5 & 1.61 & 2.83 & 1.58 & 1.45 \\
\hline 1999 & 10 & 1.91 & 3.48 & 1.85 & 1.60 \\
\hline \multicolumn{6}{|c|}{$\begin{array}{l}\text { Multivariate analysis adjusted for gender, maternal age, parity, birth year, decile and birth year* decile, } \\
\text { year*age, year* parity, decile*age, decile* parity. } \\
\text { *Odds ratio with reference category Deprivation Index decile } 1,1980 . \\
\text { *Odds ratios for the } 20-28 \text { week category did not reach statistical significance. }\end{array}$} \\
\hline
\end{tabular}

ratios are derived from multivariate modelling and include interaction terms that adjust for differences in maternal age, parity, and Deprivation Index decile over the 20 year period, as well as terms that adjust for differences in maternal age and parity by decile of deprivation. Such corrections were necessary as age distribution by Deprivation Index decile changed markedly during the study period, with teenage pregnancies among decile 10 mothers falling from $20.3 \%$ in 1980 to $12.9 \%$ in 1999 , while for decile 1 mothers births in the $35+$ age group rose from $4.7 \%$ in 1980 to $18.4 \%$ in 1999 . Odds ratios for each gestational age group category thus compare risk of preterm birth with the lowest risk group, that of decile 1 women in 1980. As this table demonstrates, risk of preterm birth increased most dramatically over the study period among those born at less than 28 weeks gestation, although the numbers in this category were small and the differences did not reach statistical significance. Significant but smaller increases in risk were seen for the other gestational age categories.

Table 3 is derived from the adjusted multivariate odds ratios calculated in table 2 and reflects the risk of preterm birth for decile 10 mothers, as compared to decile 1 mothers within each year. It is thus an approximation of the social gradient in preterm birth for that year. For births prior to 28 weeks gestation there was a modest, non-statistically significant increase in the social gradient over time, with those in decile 10 experiencing higher risks of preterm births in 1999 than they did in 1980. As gestational age increased over 28 weeks, however, this social gradient began to disappear. Thus for births in the 33-36 week category, the $48 \%$ additional risk experienced by decile 10 women in 1980 was reduced to $19 \%$ by 1999 .

Figure 3 summarises changes in preterm birth rates by baby's ethnic group between 1980 and 1994. As mentioned previously, changes in the definitions of ethnicity in 1995 make data before and after this year incomparable and thus ethnicity is not included in final models for the full dataset. During this period preterm birth rates among Maori and Pacific Islander infants both fell by $4.7 \%$, from $6.4 \%$ to $6.1 \%$ for Maori and from $4.2 \%$ to $4.0 \%$ for Pacific infants. In contrast, rates among the "other" ethnic group rose by $27.5 \%$, from $4.0 \%$ in 1980 to $5.1 \%$ in 1994 .

At univariate level, Maori infants were more likely to be delivered preterm than infants from "other" ethnic groups (OR 1.44; 95\% CI: 1.40 to 1.48 ). This decreased slightly but remained significant in the multivariate model (OR 1.29; 95\% CI: 1.26 to 1.33 ). Pacific infants showed no difference in risk compared to infants from "other" ethnic groups at the univariate level (OR 1.02; 95\% CI: 0.98 to 1.06) but this became slightly protective in multivariate modelling (OR 0.95; 95\% CI: 0.91 to 0.99 ).

Finally during this period, stillbirth rates for those 28 weeks gestation and over fell by $54 \%$, from $0.63 \%$ in 1980 to $0.29 \%$ in 1999, with the most rapid declines occurring between 1980 and 1993. Thereafter stillbirth rates remained relatively static. 
Table 3 The "social gradient in preterm birth"; risk of preterm birth among decile 10 women compared to decile 1 women (same year), New Zealand singleton live births 1980, 1990, and 1999

\begin{tabular}{|c|c|c|c|c|}
\hline \multirow[b]{2}{*}{ Year } & \multirow[b]{2}{*}{$\begin{array}{l}\text { All preterm } \\
\mathrm{OR}^{*}\end{array}$} & \multicolumn{3}{|c|}{ Gestational age category } \\
\hline & & $\begin{array}{l}20-28 w^{* *}(n=2693) \\
\text { OR* }^{*}\end{array}$ & $\begin{array}{l}29-32 \text { wk }(n=12669) \\
\text { OR* }\end{array}$ & $\begin{array}{l}33-36 \text { wk }(n=36266) \\
\text { OR* }^{*}\end{array}$ \\
\hline 1980 & 1.67 & 1.28 & 1.66 & 1.48 \\
\hline 1990 & 1.50 & 1.37 & 1.47 & 1.32 \\
\hline 1999 & 1.37 & 1.46 & 1.32 & 1.19 \\
\hline
\end{tabular}

Multivariate analysis adjusted for gender, maternal age, parity, birth year, decile, and birth year* decile, year ${ }^{*}$ age, year* parity, decile*age, decile* parity

*Odds ratios for preterm birth among decile 10 women compared to those in decile 1 for each particular year reflects to social gradient for that year.

**Odds ratios for the 20-28 week category did not reach statistical significance.

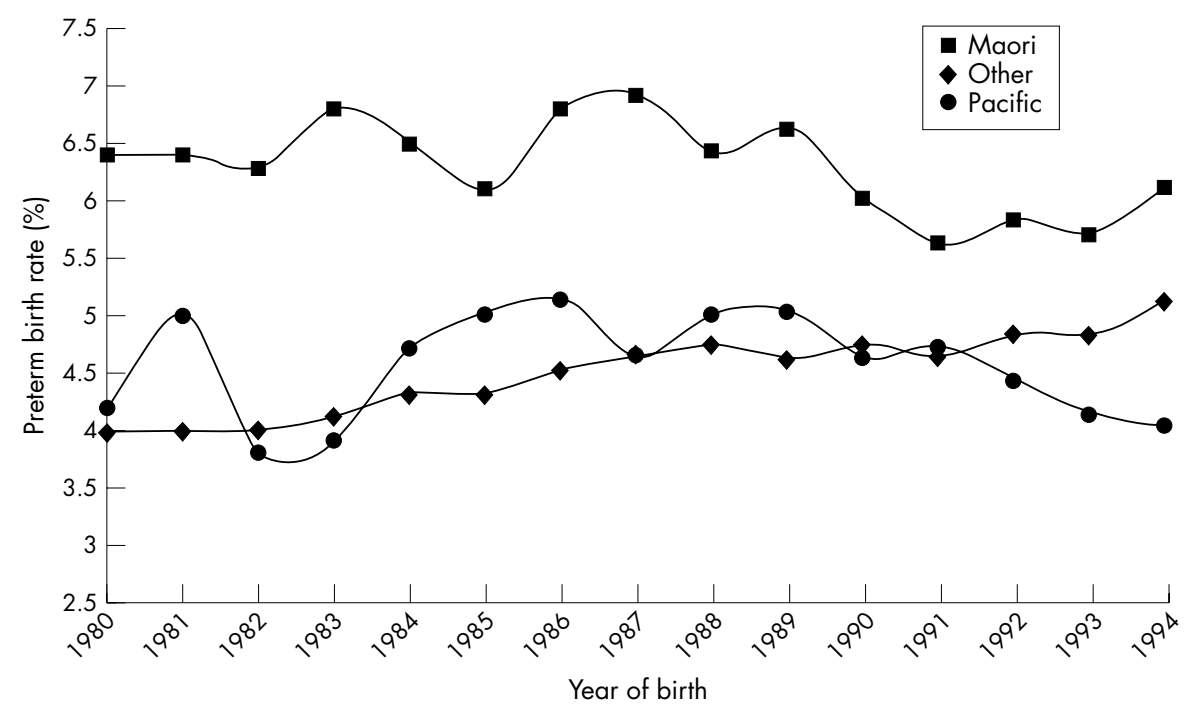

Figure 3 Rates of preterm birth by ethnic group; New Zealand singleton live births 1980-94.

\section{DISCUSSION}

In New Zealand during the period 1980 to 1999 rates of singleton preterm birth rose from $4.3 \%$ to $5.9 \%$, with the largest absolute increases occurring among infants born after 32 weeks gestation. This rise is higher than that reported by many other developed countries and appears to be confined to specific socioeconomic and ethnic subsections of the New Zealand population.

A number of possible explanations have been put forward for the apparent rise in preterm births that has occurred in some other developed countries over the past two decades. ${ }^{2}$ One possibility is an increasing reliance on ultrasound dating of pregnancy, rather than the traditionally used LMP. Ultrasound dating has been shown in a number of studies to reduce the estimated duration of pregnancy by several days and as a consequence to increase the rates of preterm birth in the populations studied. ${ }^{7}$ Whether this was responsible for the rise in preterm birth rates seen in New Zealand during the 1990s is debatable, as ultrasound scanning had become routine in many New Zealand hospitals by the late 1980s. Bange and Gendall, ${ }^{8}$ in a records based study at Waikato Hospital in 1984 , noted that $92.6 \%$ of all antenatal patients over a six month period had undergone at least one ultrasound scan, with $86.2 \%$ of patients being scanned prior to 26 weeks gestation. A similar study in Dunedin during 1988-89 documented an antenatal scanning rate of $74 \%{ }^{9}$ While small increases in antenatal scan uptake over the next decade may have continued to influence preterm birth rates, it is questionable whether this would have been of sufficient magnitude to account for the majority of the change seen during this period.
Similarly changes in birth registrations and the age of viability may have influenced preterm birth rates at earlier gestations. In 1995 changes in legislation altered stillbirth notification requirements, with the traditional gestational age of 28 weeks being reduced to 20 weeks. Thus live born infants who at very early gestations may have been considered non-viable, after 1995 legally required assignment to a live or stillbirth category. The two- to threefold increase in preterm birth rates seen among infants in the $<29$ weeks category possibly reflects this transition, although no marked increases were evident among this group during 1995. Changes in birth registration, however, are unable to explain the marked rise in preterm birth rates among infants born after 28 weeks, who in absolute terms make the largest contribution to the increases seen in New Zealand over the past two decades.

In addition increased obstetric surveillance, as shown by the marked decline in stillbirth rates during the period 198099 , may have increased preterm birth rates among those previously at risk of delivering a stillborn infant. During this period stillbirth rates fell from $0.63 \%$ to $0.29 \%$, with the most rapid declines occurring between 1980 and 1993. In contrast rates of preterm birth rose from $4.3 \%$ to $5.9 \%$ during the same period, with the most rapid rises occurring after 1990. Unfortunately, the numbers of stillbirths averted cannot be assumed to have a one-to-one correlation with the number of additional indicated preterm deliveries occurring during this period, as several infants may have had to be delivered early to avert a single in utero death. Thus the impact of increased obstetric intervention during this period, while probably considerable, is difficult to quantify using the data available. 
Another possible cause of increasing preterm birth rates is assisted conception, which has been shown to increase the risk of preterm births among women becoming pregnant by this means. While little information is available on the total numbers of assisted conceptions in New Zealand over the past 20 years, deliveries resulting from IVF/GIFT rose from 160 in 1994 to 274 in $1997,{ }^{10}$ with preterm birth rates among singletons ranging from $12.5 \%$ for GIFT pregnancies to $12.7 \%$ for IVF pregnancies. ${ }^{10}$ In absolute terms these two procedures probably account for a total 35 additional preterm births per year or an increase in rate of $0.07 \%$. The contribution other forms of infertility treatment made to preterm birth rates, however, may be somewhat higher.

While each of these factors may have made a small but significant contribution to the changing preterm birth rates over the past 20 years, they are unable to adequately explain the marked rises seen among the more affluent sections of the population. While in 1980 socioeconomic gradients in preterm birth were similar to those reported in other developed countries, ${ }^{11}{ }^{12}$ by 1999 virtually no socioeconomic gradient in preterm birth existed in New Zealand. As table 3 shows, it is births among infants over 28 weeks gestation that account for the bulk of this change, with social gradients among those born under 28 weeks moving in the opposite direction. This paradox is biologically plausible, as a number of studies have suggested that the role of infection in preterm birth is inversely related to gestational age. Notably, preterm births between 34 and 36 weeks gestation are rarely associated with infection, while those less than 30 weeks gestation typically have an infectious origin. ${ }^{13}$ Persisting social gradients in preterm birth at very early gestations could thus be possibly explained by an ongoing social gradient in genital tract infection. ${ }^{14}$ The loss of a social gradient at later gestations, however, while being partially explained by changes in maternal age and parity, suggests another aetiology.

Known risk factors that could possibly account for changes in preterm birth rates at later gestations include maternal smoking, low prepregnancy weight, stress, anxiety, and maternal workload. ${ }^{15}$ In New Zealand over the past two decades smoking rates among women 15-34 years have shown a modest decline, from $36 \%$ at the 1981 census to $28 \%$ by $1996 .{ }^{16}$ Whether such figures reflect smoking patterns during pregnancy, however, is uncertain. Similarly little information is available on changes in prepregnancy weight during this period, although the 1997 National Nutrition Survey indicated that rates of obesity among females had risen from $13 \%$ in $1989-90$, to $19 \%$ in 1997 , with obesity among women of reproductive age in 1997 being in the order of $17 \% .{ }^{17}$ Thus it is unclear whether changes in the prevalence these two risk factors could have contributed to the rise in preterm births seen during this period.

Women's participation in the workforce is another potential explanation for the loss of social gradient among higher gestation preterm births. Kelsey, ${ }^{18}$ when commenting on the impact of a period of promarket reform that began in New Zealand in the mid 1980s, noted that during this period a fall in real wages placed pressure on all adult members of households to join the workforce, especially part time and that employment tended to cluster around households who already had jobs. Whether this significantly increased women's workforce participation is difficult to determine, as baseline trends in New Zealand have shown a steady increase from $47.2 \%$ in 1981 to $57.9 \%$ in $1996,{ }^{19}$ in keeping with international trends. ${ }^{20}$ In addition, number of hours worked increased markedly, with the period 1994 to 1999 seeing a $29.2 \%$ increase in women working 45-49 hours per week and a $28 \%$ increase in women working 50 hours or more. ${ }^{19}$
Whether such changes impacted significantly on rates of preterm birth, either directly or via their effects on perceived stress, is difficult to determine, although several studies have shown strong associations between the number of hours worked and preterm delivery, especially among nulliparous women. ${ }^{21} 22$

Thus while a number of possible explanations exist for New Zealand's increasing preterm birth rates over the past 20 years, none alone is sufficient to account for the magnitude of change seen. In addition, data limitations prevent the differentiation of preterm birth into its iatrogenic and idiopathic subcategories, making it difficult to assess the impact of obstetric intervention during this period. Thus further research is necessary if the apparent increases in preterm birth over the past 20 years are to be fully understood. Similarly, reviews from other developed countries may be necessary to determine whether these findings are restricted to New Zealand or an emerging international trend.

\section{ACKNOWLEDGEMENTS}

Dr ED Craig is currently funded by a Training Fellowship from the Health Research Council of New Zealand. Dr JMD Thompson is currently funded by a Child Health Research Foundation Rotary Research Fellowship.

Authors' affiliations

E D Craig, J M D Thompson, E A Mitchell, Department of Paediatrics, University of Auckland, New Zealand

\section{REFERENCES}

1 Ventura S, Martin J, Curtin S, et al. Births. Final data for 1998. National Vital Statistics Reports 2000;48:14-15.

2 Joseph K, Kramer M, Marcoux S, et al. Determinants of preterm birth rates in Canada from 1981-1983 and from 1992-1994. N Engl J Med 1998:339:1434-9.

3 Day P, Sullivan E, Ford J, Lancaster P. Australia's mothers and babies 1997. Perinatal Statistics Series no. 9. Sydney: Australian Institute of Health and Welfare, National Perinatal Statistics Unit, 1999:28-9.

4 Breart G, Blondel B, Tuppin P, et al. Did preterm deliveries continue to decrease in France in the 1980s? Paediatr Perinat Epidemiol 1995;9:296-306.

5 Kramer $M$, Platt R, Yang $H$, et al. Secular trends in preterm birth. JAMA 1998;280:1849-54.

6 Crampton P, Salmond C, Sutton F. NZDep9 1: A new Index of Deprivation. Social Policy Journal of New Zealand 1997;9: 186-93.

7 Bakketieg L. Current growth standards, definitions, diagnosis and classification of fetal growth retardation. Eur J Clin Nutr 1998;52:S1-S4

8 Bange D, Gendall P. Routine antenatal ultrasound: a retrospective audit. N Z Med J 1987; 13:284-6.

9 Buckenham T, Spears G, Teele R. Antenatal ultrasonography in Dunedin: one years data. N Z Med J 1991;104:117-19.

10 Hurst T, Shafir E, Lancaster P. Assisted conception, Australia and New Zealand 1997. Assisted Conception Series. 1999;4.

11 de Sanjose S, Roman E. Low birth weight, preterm and small for gestational age babies in Scotland, 1981-1984. J Epidemiol Community Health 1991;45:207-10.

12 Lumley J. How important is social class a factor in preterm birth? Lancet 1997;349:1040-1.

13 Lu G, Goldenberg R. Current concepts on the pathogenesis and markers of preterm birth. Clin Perinatol 2000;27:263-83.

14 Kramer M, Seguin L, Lydon J, Goulet L. Socioeconomic disparities in pregnancy outcome: why do the poor fare so poorly. Paediatr Perinat Epidemiol 2000;14:194-210.

15 Kramer M. Determinants of low birth weight: methodological assessment and meta-analysis. Bull WHO 1987;65:663-737.

16 Laugesen M. Tobacco statistics. Wellington: Cancer Society of New Zealand Inc., 2000:6.

17 Ministry of Health. Progress on health outcome targets. Wellington: Ministry of Health, 1999:29-33.

18 Kelsey J. The economic deficit. In: Kelsey J, ed. The New Zealand experiment. Auckland: Auckland University Press, 1996:243-70.

19 Statistics New Zealand. New Zealand official yearbook 2000. Auckland: Statistics New Zealand, 2000:317-20.

20 Reich R. The lure of hard work. In: Reich R, ed. The future of success New York: Random House, 2001:111-31.

21 Newman R, Goldenberg R, Moawad A, et al. Occupational fatigue and preterm premature rupture of the membranes. Am J Obstet Gynecol $2001 ; 184: 438-46$.

22 Mamelle N, Laumon B, Lazar P. Prematurity and occupational activity during pregnancy. Am J Epidemiol 1984;1 19:309-22. 


\section{LETTERS}

If you have a burning desire to respond to a paper published in $A D C$ or $F \& N$, why not make use of our "rapid response" option?

Log on to our website (www.archdischild. com), find the paper that interests you, click on "full text" and send your response by email by clicking on "submit a response".

Providing it isn't libellous or obscene, it will be posted within seven days. You can retrieve it by clicking on "read eletters" on our homepage.

The editors will decide, as before, whether to also publish it in a future paper issue.

\section{Amiodarone and breast feeding}

An infant was born at $33+2$ weeks gestation by caesarean section after an in utero diagnosis of fetal ascites and tachycardia. The mother had received treatment during pregnancy with flecainide, amiodarone, and propranolol. The amiodarone was prescribed initially at $200 \mathrm{mg}$ three times a day and was reduced to twice a day after 11 days.

The mother was keen to breast feed the baby. In previous reports of amiodarone and breast feeding, amiodarone treatment was for a maternal indication and hence continued post partum. ${ }^{12}$ In this case, the amiodarone treatment stopped at delivery. However, because of the long terminal half life of amiodarone (about 50 days $^{3}$ ), it could take several months for the level to fall. As one of the adverse effects of amiodarone is thyroid toxicity, the baby's thyroid function was assessed and found to be normal. A decision was made to allow the mother to breast feed, and the baby was closely monitored.

Breast milk was sent for analysis to determine the amiodarone level on days 5, 11 , 18 , and 25. It had increased on day 11 (2.1 $\mathrm{mg} / \mathrm{l})$ compared with day $5(0.6 \mathrm{mg} / \mathrm{l})$. This may be due to changes in composition of the milk. We do not know at what time of day the milk was expressed or whether the sample was taken at the beginning or the end of the feed. The fat content of the milk was likely to be greater after 11 days than after 5 days, which may affect the distribution of amiodarone. McKenna et al described changes in amiodarone concentration in breast milk throughout the day. By 25 days, amiodarone was undetectable. Throughout this period the baby remained well and thyroid function was normal.

Although we would not recommend that breast feeding is necessarily safe for all babies exposed to amiodarone, this case illustrates that, in some circumstances, with close monitoring, breast feeding can be initiated.

C M Hall

Pharmacy Department, Royal Victoria Infirmary, Queen Victoria Road, Newcastle upon Tyne NE 1 4LP, UK; catherine.hall@trvi.nuth.northy.nhs.uk

K P B McCormick

Neonatal Unit, Royal Victoria Infirmary

\section{References}

1 Plomp TA, Vulsma T, de Vijlder JJM. Use of amiodarone during pregnancy. European Journal of Obstetrics and Gynecology and Reproductive Biology 1992;42:201-7.

2 Pitcher D, Leather HM, Storey GCA, et al. Amiodarone in pregnancy. Lancet Amiodarone in

3 Sanofi-Synthelabs. Summary of product characteristics, Cordarone X. Sanofi-Synthelabo, UK

4 McKenna WJ, Harris L, Rowland E, et al. Amiodarone therapy during pregnancy. Am J Cardiol 1983;51:1231-3

\section{Reducing antibiotic use on the neonatal unit by improving communication of blood culture results: a completed audit cycle}

It is common clinical practice to discontinue antibiotic treatment of asymptomatic babies if the blood cultures are negative at 48 hours. ${ }^{1-3}$ However, if blood culture results are only available during the normal working day, then antibiotic treatment of some babies may continue into the next working day. In our neonatal unit, blood culture results were routinely received from the microbiology laboratory via fax as a list every morning. Extra positive results would be telephoned through, if they became available, during the normal working day. Results could also be checked by the clinical staff telephoning the laboratory during "office hours". This gave the potential for inadvertent prolongation of antibiotic courses for up to a day. In a previous study, McDonald et $a l^{4}$ found this to be a common occurrence. It is of concern because unnecessary antibiotic use may contribute to antibiotic pressure within the neonatal unit and may encourage the selection of drug resistant organisms.

We performed two audits into this problem within our neonatal unit. Our audit standard on each occasion was that antibiotics should be stopped at 48 hours, if blood cultures were negative, unless a decision to continue was clearly documented in the case notes. Babies with negative blood cultures were identified from the microbiology database. Each episode was classified into one of four groups: (a) antibiotics not started; $(b)$ antibiotics stopped within 48 hours; (c) antibiotics given for more than 48 hours deliberately; (d) antibiotics given for more than 48 hours unintentionally. The results are summarised in table 1.

The first audit was conducted on 45 babies with negative blood cultures between January 1997 and December 1998. We were able to collect complete data from case notes and drug charts for $376(83.4 \%)$ of these blood cultures. We found that the audit standard was not met in 144/376 (38.3\%). The median (range) duration of antibiotic treatment for each baby was 60 (16.9-332) hours.

The blood culture analyser in use in our laboratory (BacT/Alert Microbial Detection System; Organon Teknika Corporation, Durham, North Carolina, USA) tests for bacterial growth every 10 minutes and communicates the blood culture status (positive or negative) to a computer. After our initial audit, we established a computer link between the blood culture analyser and the neonatal unit. This allows the clinical staff to check the status of any blood culture in the analyser in real time, 24 hours a day.

The second audit was performed on babies with negative blood cultures between May 2000 and August 2000. Two hundred negative blood cultures were identified. Complete data were available for 179/200 (89.5\%). The audit standard was not met in only $20 / 179$ (11.2\%); $\mathrm{p}<0.001$ compared with the first audit. The median (range) duration of treatment was reduced to $48(1-182)$ hours $(\mathrm{p}<0.0001)$. There was an overall reduction of two doses of antibiotic per baby (from a mean of 8.8 to 6.8 doses per baby).

Overall, we estimated that we gave 21684 doses of antibiotics on the neonatal unit between January 1997 and December 1998. If the computer system had been in operation during this period, we estimate that we could have reduced this by $16.2 \%$ to 18169 . We think that this magnitude of reduction in antibiotic pressure on the neonatal unit is worth achieving.

M A Jardine, Y Kumar, S Kausalya, S Harigopal, J Wong, A Shivaram, T J Neal, C W Yoxall

Correspondence to: Dr Yoxall, Liverpool Women's Hospital, Crown Street, Liverpool L8 7SS, UK; Bill.Yoxall@|wh-tr.nwest.nhs.uk

Table 1 Reduction in unintentional antibiotic use over 48 hours after introduction of real time availability of blood culture status by a computer link between the blood culture machine and our neonatal unit

\begin{tabular}{llllr}
\hline Results & No antibiotics started & $\begin{array}{l}\text { Antibiotics stopped after } \\
<48 \mathrm{~h}\end{array}$ & $\begin{array}{l}\text { Antibiotics continued for } \\
>48 \mathrm{~h} \text { deliberately }\end{array}$ & $\begin{array}{c}\text { Antibiotics continued } \\
>48 \mathrm{~h} \text { unintentionally }\end{array}$ \\
\hline First audit & $25(6.6 \%)$ & $132(35.1 \%)$ & $75(19.9 \%)$ & $144(38.3 \%)$ \\
Second audit & $15(8.4 \%)$ & $117(65.4 \%)$ & $27(15.1 \%)$ & $20(11.2 \%)$ \\
\hline
\end{tabular}




\section{References}

1 Pichichero ME, Todd JK. Detection of neonatal bacteremia. J Pediatr 1979;94:958-60.

2 Rowley AH, Wald ER. Incubation period necessary to detect bacteremia in neonates. Pediatr Infect Dis J 1986:5:590-1.

3 Hurst MK, Yoder BA. Detection of bacteremia in young infants: is 48 hrs adequate? Pediatr Infect Dis J 1995; 14:711-13.

4 McDonald M, Moloney A, Clarke TA, et al. Blood cultures and antibiotic use in a neonatal intensive care unit. Ir J Med Sci 1992;161:3-4.

\section{Swaddling and heat loss}

The letter of Hawkes et al ${ }^{1}$ raises the important issues of swaddling and temperature on admission to the neonatal unit. Besch et al carried out a limited comparison of different swaddling materials and found a transparen plastic bag together with radiant heat to be effective in preventing heat loss in infants over $2 \mathrm{~kg}$. Following a report in the literature, ${ }^{3}$ we have begun wrapping all preterm infants $<1000 \mathrm{~g}$ in a thin plastic wrap. The wrap is preheated on a radian warmer and the infant is immediately placed (undried) on the plastic sheet, which is folded over to completely (but loosely) enclose the torso and extremities from the neck down. The infant is left in the wrap until transported to the neonatal unit and the temperature has stabilised in a humidified environment. The median temperature of the $19<1000$ infants admitted since wrapping was commenced was $36.7^{\circ} \mathrm{C}$ on arrival to the nursery compared with $35.5^{\circ} \mathrm{C}$ for the previous 86 unwrapped infants ( $\mathrm{p}=0.002$; using MannWhitney U test). There were no significan differences in birth weight, gestational age or Apgar scores between the groups.

Although our experience is in smalle preterm infants (who are more prone to hypothermia), our results are in keeping with those of Vohra et al, who studied infants $<32$ weeks. ${ }^{3}$ We now plan to wrap all preterm infants $<1500 \mathrm{~g}$.

The plastic wrap is likely to be more effective than towels because of reduction in evaporative heat loss and because it allows observation of the infant. However, the plastic wrap is unlikely to significantly reduce radiant heat loss, so an additional heat source is essential for preterm infants. Some form of head swaddling is also important and needs further study. Aluminum foil may reduce evaporative, convective, and radiant heat loss but does not allow observation or radian warming.

It appears there are many aspects of swaddling that require further investigation.

M P Meyer

Neonatal Paediatrician, Neonatal Unit, KidzFirst Middlemore Hospital, Auckland, New Zealand and the University of Auckland mmeyer@middlemore.co.nz

\section{References}

1 Hawkes DJ, Spendley DG, Alfaham M. Hypothesis waiting for proof: unwrapping neonates for transfer. Arch Dis Child Fetal Neonatal Ed 2002;87:F232

2 Besch NJ, Perlstein PH, Edwards NK, et al The transparent baby bag: a shield against heat loss. N Engl J Med 1971;284:121-4.

3 Vohra S, Frent G, Campbell V, et al. Effect of polyethylene occlusive skin wrapping on heat oss in very low birth weight infants at delivery: a randomized trial. J Pediatr 1999; 134:547-551.

\section{Preventing hypothermia at birth in preterm babies: at a cost of overheating some?}

In the Epicure study, the odds ratio of death before discharge for babies whose temperature on admission to the neonatal unit was $>35^{\circ} \mathrm{C}$ was 0.58 (95\% confidence interval (CI) 0.39 to 0.85) compared with those with lower temperatures. ${ }^{1}$ In 2001, we therefore introduced a policy of wrapping neonates $<30$ weeks gestation in polythene bags at birth without first drying them. Temperatures on admission to the neonatal unit after the introduction of this policy were compared with those of historica controls of $<30$ weeks gestation admitted unwrapped between 1996 and 2000. The admission temperatures were analysed by stepwise multiple regression against being "bagged" or not, time to admission to the unit, birth weight, gestation, mode of delivery, month of delivery, and maternal temperature Significant coefficients of variation existed between admission temperature and

- being bagged $+0.35^{\circ} \mathrm{C}(0.09$ to 0.62$)$ (coefficient, 95\% CI):

- time to admission $-0.02^{\circ} \mathrm{C}(-0.01$ to -0.03$)$ per minute;

- birth weight $+0.07^{\circ} \mathrm{C}(0.02$ to 0.1$)$ per $100 \mathrm{~g}$;

- gestation $+0.0007^{\circ} \mathrm{C}(0.0002$ to 0.001$){ }^{\circ} \mathrm{C}$ per week.

Thus "bagging" increased admission temperatures by $0.35^{\circ} \mathrm{C}$, which is rather less than the rise of $1.9^{\circ} \mathrm{C}$ in babies $<28$ weeks gestation reported in a previous study.

Table 1 shows that, in the comparable groups, this rise of $0.35^{\circ} \mathrm{C}$ resulted in a significant reduction in incidence of hypothermia $\left(<35.5^{\circ} \mathrm{C}\right)$ in "bagged" babies. However significantly more of them (12\%) were hyperthermic $\left(>37^{\circ} \mathrm{C}\right)$, a phenomenon previously reported but not discussed. ${ }^{2}$ The risks of hyperthermia are less well defined than those of hypothermia, but it may increase the risk of neurological damage, particularly after ischaemia. ${ }^{3}$ The technique of wrapping babies in polythene bags would seem to benefit very preterm babies, although we may yet have to learn to use it appropriately.

T Newton, M Watkinson Neonatal Unit, Birmingham Heartlands Hospital Birmingham, UK michael.watkinson@heartsol.wmids.nhs.uk

\section{References}

1 Costeloe K, Hennessy E, Gibson AT, et al. The EPlcure study: outcomes to discharge from hospital for infants born at the threshold of viability. Pediatrics 2000;106:659-71.

2 Vohra S, Frent G, Campbell V, et al. Effect of polyethylene occlusive skin wrapping on heat loss in very low birth weight infants at delivery: a randomised trial. J Pediatr 1999; 134:547-51.
3 Gunn AJ, Bennet L. Is temperature important in delivery room resuscitation? Semin Neonatol $2001 ; 6: 241-9$.

\section{Technique for insertion of percutaneous central venous catheters in the newborn period}

The use of percutaneous central venous catheters is of proven value for the provision of parenteral nutrition and intravenous drug treatment in neonates. They have become an integral part of the management of very low birthweight infants in most intensive care units.

At the Royal Children's Hospital in Melbourne we used a silastic catheter, which has an external diameter of $0.6 \mathrm{~mm}$ and comes in a variety of different lengths (Epicutaneocava catheter manufactured by Vygon lengths 15, 30, and $50 \mathrm{~cm}$; ref nos 2184.015 2184.00, and 2184.005; cost AU\$59.10). It is packaged with a metal 19 GA butterfly needle for use in insertion of the line.

This technique has some drawbacks.

(1) The 19 GA needle is difficult to put directly into neonatal veins because of its large size.

(2) It can be difficult to appreciate "flash back" of blood into the metal needle.

(3) It is not possible to "flush" the needle to ensure correct positioning of the line as well as patency of the vessel.

(4) It is not feasible to place femoral venous lines using this method.

We therefore use a method whereby the vein, using the Seldinger technique, is ultimately cannulated with a 20 GA catheter through which the silastic line can be inserted.

(1) The procedure should be carried out under optimal conditions using an aseptic technique. If the infant is already ventilated, we advocate the use of a muscle relaxant as well as adequate sedation. This is especially advisable for insertion of femoral venous lines.

(2) The vein is initially cannulated with a 24 GA (external diameter $0.7 \mathrm{~mm}$ ) cannula. The sites most often used are the great saphenous vein at the ankle or knee joint, the femoral vein, the basilic or cephalic veins in the antecubital fossa, or, occasionally, the superficial temporal vein. A transilluminator or "cold light" inserted into the finger of a sterile glove can be of use in locating deep veins as well as protecting the sterile field.

(3) A guidewire is then inserted through the cannula into the vein. We use a "duoflex spring wire guide": diameter $0.45 \mathrm{~mm}$, length $25 \mathrm{~cm}$ (duoflex spring wire guide manufactured by Arrow; product no AW-04018; cost

Table 1 Incidence of hypothermia and hyperthermia in control babies and babies wrapped in polythene bags (study group)

\begin{tabular}{llll}
\hline & Control group & Study group & Difference $(95 \% \mathrm{Cl})$ \\
\hline Number & 230 & 48 & - \\
Gestation (weeks) & $27.5(23-29)$ & $28(23-29)$ & - \\
Weight $(g)$ & $1020(400-1900)$ & $1027(500-1700)$ & - \\
Number $<35.5^{\circ} \mathrm{C}$ & $96(42)$ & $12(25)$ & $-17(-2$ to -29$)$ \\
Number $>37.0^{\circ} \mathrm{C}$ & $1(0.4)$ & $6(12.5)$ & $12(5$ to 24$)$ \\
\hline
\end{tabular}

Values are either median (range) or number $(\%)$

$\mathrm{Cl}$, Confidence interval. 
AU\$13.00; Insyte intravenous catheter manufactured by Becton Dickinson catheter; GA 24, 22, and 20; cost AU \$2.00). This has the advantage of having a soft tip at both ends of the wire and being a snug fit to the smallest catheter. Care must be taken not to advance the wire if any resistance is met.

(4) A small nick is made in the skin at the site of wire to facilitate the insertion of the larger intravenous cannulae.

(5) A 20 GA (external diameter $1.1 \mathrm{~mm}$ ) cannula is then threaded over the wire into the vein (a $22 \mathrm{GA}$ (external diameter $0.8 \mathrm{~mm}$ ) can be used to dilate the vein before the larger cannula is inserted). This can be flushed with saline to ensure patency of the vein.

(6) The silastic catheter can then be fed up the vein through the $20 \mathrm{GA}$ cannula with a pair of toothless forceps. Occasionally the silastic line coils up in the hub of the cannula. This can be overcome by cutting the cannula flush to the hub and reinserting the silastic line.

(7) The silastic catheter is placed to the required length and the other cannula is withdrawn.

(8) The silastic catheter should be placed outside the cardiac outline in accordance with new guidelines. ${ }^{1-3}$ The position is always confirmed radiologically either by plain radiograph or, if necessary, by injection of radioopaque dye. We have seen neonates with pericardial tamponade associated with malpositioned catheters, which has been well documented in the literature. ${ }^{1-3}$

We have found this method to be extremely reliable in the insertion of percutaneous venous catheters.

The use of the guidewire incurs additional costs (see above). In our experience these are partially offset by an improved success rate using the above method. We do not open the silastic catheter until the $20 \mathrm{GA}$ is in place within the vein. This means that a line is not wasted if the vein cannot be cannulated.

G Bayley

Bristol School of Anaesthesia, Bristol, UK

Correspondence to: Dr Bayley, Department of Anaesthetics, Bristol Royal Infirmary, Marlborough Street, Bristol, UK; kateandguy@hotmail.com

\section{References}

1 Darling JC, Newell SJ, Mohamdee O, et al. Central venous catheter tip in the right atrium: a risk factor for neonatal cardiac tamponade. J Perinatol 2001;21:461-4.

2 Darling JC, Newell SJ, Dear PRF, et al. Placement of neonatal central venous catheter tips in the right atrium: a practice to be avoided? Arch Dis Child Fetal Neonatal Ed 2001:85:F146.

3 Mehta NM, Nicholl RM. Positioning of long lines. Arch Dis Child Fetal Neonatal Ed 2002;86:F68-9.

\section{Umbilical granulomas: a randomised controlled trial}

The Archimedes section has previously contained a brief section on the treatment of umbilical granulomas. ' We have now conducted a randomised controlled trial of the management of umbilical granulomas. The trial compared silver nitrate cauterisation with the use of alcoholic wipes at each nappy change (conservative management). The impetus for this work was a series of three burns to the anterior abdominal wall after silver nitrate cauterisation, seen in a single London hospital over a two year period.

The trial aimed to show equivalence between the two treatment modalities. On the basis of equal efficacy, we intended to change practice to conservative management. More than 40 infants were referred, but a large number of parents chose conservative management rather than randomisation. Difficulty in recruitment meant there were inadequate numbers to show statistical significance within the limited time span available.

The salient results were that two of three granulomas resolved over a three week period without cauterisation. Those infants whose granulomas did not resolve went on to treatment with cauterisation following a protocol that involved drying the area both before and after silver nitrate application, surrounding the umbilicus with white soft paraffin, and leaving the area exposed for 10 minutes after application. This resulted in resolution in all remaining cases without harm due to delay in treatment.

On the basis of this work, we suggest a change in current practice to initial conservative management followed by cauterisation only when conservative treatment fails.

J Daniels Homerton Hospital, London, UK

F Craig

Great Ormond Street Hospital, London, UK

R Wajed

Northwick Park Hospital, London, UK

$M$ Meates

North Middlesex Hospital, London, UK

Correspondence to: Dr Daniels, Homerton Hospital, London, UK; Justin.Daniels@virgin.net

\section{Reference}

1 Daniels J. Is silver nitrate the best agent for the management of umbilical granulomas? Arch Dis Child 2001;85:452.

\section{Progressive ventricular dilatation (PVD) over the past 22 years}

We read with interest the article of Murphy et $a l,{ }^{1}$ and it prompted us to review our own experience with progressive ventricular dilatation (PVD) over the past 22 years at the
Maine Medical Center (MMC). Since 1980, we have used a single approach to management of PVD. As noted in previous publications, we have considered the need for intervention to be rapid head growth defined as an increase in occipitofrontal circumference of $2 \mathrm{~cm}$ a week or more rather than relying on imaging. ${ }^{23}$ As this degree of head growth suggests increased intracranial pressure, ${ }^{4}$ we have intervened by directly draining ventricular fluid through a 21 gauge angiocath placed through the right coronal suture into the right lateral ventricle. This catheter is connected to a ventriculostomy drainage system, and drainage is continued for seven days if possible. The catheter is then removed and the decrease in head circumference and ventricular size recorded. The infant is watched for return of rapid head growth, and an angiocath is reinserted as needed. This procedure is repeated until the infant reaches about $2 \mathrm{~kg}$ in weight, and if rapid head growth continues, a permanent ventriculoperitoneal shunt is placed. ${ }^{3}$ We do not use pharmacological treatment or repeat lumbar puncture to treat PVD.

As pointed out by Murphy et al, PVD sufficient to require intervention occurs almost exclusively in infants with grade 3 or 4 intraventricular haemorrhage (IVH). As expected, the very low birthweight infants with high grade IVH have a high mortality. Table 1 shows a comparison between the outcomes for grade 3-4 IVH at MMC during the 1980s and over the past five years (1997-2001 inclusive), and the data of Murphy et al grouped in the same way. As noted, there is little difference over time or between studies. Overall mortality for grade 3-4 IVH was 33\% (26/79) for Murphy et al, 33\% (31/94) for MMC in the 1980s, and 31\% (9/29) for MMC in 1997-2001. Until grade 3-4 IVH can be eliminated, posthaemorraghic hydrocephalus will continue to occur with high morbidity and mortality.

L T Weissman, P J Marro, D L Kessler, D B Sobel, D L Morrow, S Boggs, W C Allan Department of Pediatrics, Maine Medical Center, Portland, Maine, USA; weissl@mmc.org

\section{References}

1 Murphy BP, Inder TE, Rooks V, et al. Posthaemorrhagic ventricular dilatation in the premature infant: natural history and predictors of outcome. Arch Dis Child Fetal Neonatal Ed 2002;87:F37-41.

2 Allan WC, Holt PJ, Sawyer LR, et al. Ventricular dilation after neonatal periventricular-intraventricular hemorrhage. Natural history and therapeutic implications. Am J Dis Child 1982;136:589-93.

3 Marro PJ, Dransfield DA, Mott SH, et al. Posthemorrhagic hydrocephalus: use of an intravenous-type catheter for cerebrospinal fluid drainage. Am J Dis Child 1991;145:1141-6.

4 Hill A, Volpe JJ. Normal pressure hydrocephalus in the newborn. Pediatrics $1981 ; 68: 623-9$

Table 1 Comparison between the outcomes for grade 3-4 intraventricular haemorrhage (IVH) in the three studies

\begin{tabular}{lccc}
\hline & Murphy et al & MMC 1980s & MMC 1997-2001 \\
\hline Grade 3-4 IVH (\% of all <1500 g) & $79(7 \%)$ & $94(6 \%)$ & $29(6 \%)$ \\
Death <14 days & $18 / 79(23 \%)$ & $29 / 94(30 \%)^{* *}$ & $8 / 29(28 \%)^{* *}$ \\
PVD requiring treatment & $34 / 61(56 \%)$ & $24 / 65(37 \%)$ & $11 / 21(52 \%)$ \\
VP shunt/late death (\% of PVD treatment) & $18 / 8(26 / 34=76 \%)$ & $12 / 3(15 / 24=63 \%)$ & $6 / 1(7 / 11=63 \%)$ \\
\hline
\end{tabular}

* Rate for all infants $<35$ weeks.

**Rate for all deaths $<30$ days.

MMC, Maine Medical Center; PVD, progressive ventricular dilatation; VP, ventriculoperitoneal. 
Do we need to assess the thyroid function in the infants of mothers with Hashimoto's thyroiditis?

We read with interest the recent comprehensive review of neonatal thyroid disorders, which gave evidence-based answers to many important questions. The author recommended that all babies born to mothers with Hashimoto's thyroiditis should be reviewed at 10 days to 2 weeks and a thyroid function test taken because infants may develop transient hypothyroidism or, very rarely, hyperthyroidism.

As paediatricians, in a hospital with a paediatric endocrine caseload similar to some tertiary centres and a subregional neonatal intensive care unit with local deliveries of 6000 per annum, we think that the potential benefits of this practice are difficult to justify. We do understand that such practice will help in identifying babies who may develop transient congenital hypothyroidism caused by maternal thyrotropin receptor blocking antibodies. However, the incidence of this form of hypothyroidism has been estimated to be 1 in 180000 normal infants ( 2\% of congenital hypothyroidism) and the majority of them will have raised thyroid stimulation hormone levels that can be detected by the current neonatal screening. ${ }^{2}$ Based on a simple calculation, in a unit of our size only one baby will be detected every 30 years. We feel that there would be major disadvantages if we are to adopt the author's recommendation. Firstly, an extra hospital visit for babies and parents; secondly the need to bleed many healthy infants; and finally the potential for confusion and unnecessary anxiety. Until objective evidence emerges about the significance of subtle thyroid dysfunction in early life we feel that the current screening programme should not be extended.

A $M$ Habeb

Paediatric Department, Hull Royal Infirmary abdul.habeb@hey.nhs.uk

M Zubier, P Pairaudeau, V Mathew Paediatric Department, Hull Royal Infirmary

\section{References}

1 Ogilvy-Stuart AL. Neonatal thyroid disorder-review. Arch Dis Child Fetal Neonatal Ed 2002;87:F165-71.

2 Brown RS, Bellisario RL, Botero D, et al. Incidence of transient congenital hypothyroidism due to maternal thyrotropin receptor-blocking antibodies in over one million babies. J Clin Endocrinol Metab 1996;81:1147-51

\section{CORRECTIONS}

In the CD Review (Arch Dis Child Fetal Neonatal Ed 2003;88:F164) reviewed by C Wren, please note that the affiliation of the authors is published incorrectly. This should have read Royal Prince Alfred Hospital, Sydney. Also, the web address in the final paragraph is incomplete. The correct address is: http://www.cs.nsw. gov.au/rpa/neonatal/default.htm. The errors are much regretted.

The authors would like to acknowledge and apologise for an error in our article Socioeconomic status and preterm birth: New Zealand trends, 1980 to 1999. ED Craig, JMD Thomp-

Table 2 Multivariate odds ratios for preterm birth by gestational age category and Deprivation Index decile; New Zealand singleton live births 1980,1990 , and 1999

\begin{tabular}{lcllll}
\hline \multicolumn{7}{c}{ Gestational age category } \\
\cline { 3 - 6 } Year & $\begin{array}{l}\text { NZDep Index } \\
\text { Decile }\end{array}$ & $\begin{array}{l}\text { All preterm } \\
(n=51711) \\
\text { OR* }\end{array}$ & $\begin{array}{l}20-27 \text { weeks } \\
(n=2697) \\
\text { OR** }\end{array}$ & $\begin{array}{l}28-33 \text { weeks } \\
(n=12703) \\
\text { OR* }\end{array}$ & $\begin{array}{l}34-36 \text { weeks } \\
(n=36311) \\
\text { OR* }\end{array}$ \\
\hline 1980 & 1 & 1.00 & 1.00 & 1.00 & 1.00 \\
1980 & 5 & 1.15 & 1.08 & 1.16 & 1.15 \\
1980 & 10 & 1.36 & 1.18 & 1.39 & 1.36 \\
1990 & 1 & 1.30 & 1.31 & 1.21 & 1.33 \\
1990 & 5 & 1.44 & 1.45 & 1.34 & 1.47 \\
1990 & 10 & 1.63 & 1.66 & 1.52 & 1.67 \\
1999 & 1 & 1.64 & 1.67 & 1.44 & 1.72 \\
1999 & 5 & 1.76 & 1.91 & 1.53 & 1.84 \\
1999 & 10 & 1.93 & 2.25 & 1.64 & 2.02 \\
\hline
\end{tabular}

Multivariate analysis adjusted for gender, maternal age, parity, birth year, decile and birth year ${ }^{*}$ decile, year* age, year* parity, decile*age, decile* parity.

${ }^{*}$ Odds ratios (OR) with reference category Deprivation Index decile 1, 1980

** Odds ratios for the 20-27 week category did not reach statistical significance.

Table 3 The "social gradient in preterm birth"; risk of preterm birth amongst decile 10 women compared to decile 1 women (same year), New Zealand singleton live births 1980, 1990, and 1999

\begin{tabular}{lllll}
\hline \multicolumn{5}{c}{ Gestational age category } \\
\cline { 3 - 5 } Year & $\begin{array}{l}\text { All preterm } \\
(n=51711)\end{array}$ & $\begin{array}{l}20-27 \text { weeks } \\
(n=2697)\end{array}$ & $\begin{array}{l}28-33 \text { weeks } \\
(n=12 ~ 703)\end{array}$ & $\begin{array}{l}34-36 \text { weeks } \\
(n=36 ~ 311) ~ O O^{*}\end{array}$ \\
\hline 1980 & 1.36 & 1.18 & 1.39 & 1.36 \\
1990 & 1.26 & 1.27 & 1.25 & 1.26 \\
1999 & 1.17 & 1.35 & 1.14 & 1.17 \\
\hline
\end{tabular}

Multivariate analysis adjusted for gender, maternal age, parity, birth year, decile and birth year ${ }^{*}$ decile, year*age, year ${ }^{*}$ parity, decile*age, decile* parity.

*Odds ratios (OR) for preterm birth amongst decile 10 women compared to those in decile 1 for each particular year reflects the social gradient for that year.

* * Odds ratios for the 20-27 week category did not reach statistical significance. 